\title{
'None of Us Sets Out To Hurt People': The Ethical Geographer and Geography Curricula in Higher Education
}

\author{
WILLIAM (BILL) E. BOYD, RUTH L. HEALEY, SUSAN W. HARDWICK, MARTIN HAIGH \\ with PHIL KLEIN, BRUCE DORAN, JULIE TRAFFORD \& JOHN BRADBEER
}

\begin{abstract}
This paper examines ethics in learning and teaching geography in higher education. It proposes a pathway towards curriculum and pedagogy that better incorporates ethics in university geography education. By focusing on the central but problematic relationships between (i) teaching and learning on the one hand and research on the other, and (ii) ethics and geography curricula, the authors' reflections illustrate how ethics may be better recognized within those curricula. They discuss issues affecting teaching and learning about ethics in geography, and through identification of a range of examples identify ways to enhance the integration of ethical issues into university geography curricula. KEY WORDS: Higher education, geography, curriculum, ethics, ethical practice, pedagogy
\end{abstract}

KEY WORDS: Higher education, geography, curriculum, ethics, ethical practice, pedagogy

\section{Introduction}

There is a trend in higher education to define graduate attributes, the professional, scholarly and personal characteristics expected of graduates of university courses arising from their university studies. At Southern Cross University, for example, this is expressed as graduates being more than the sum of the knowledge acquired through their studies and extends to the skills, values and attitudes essential for gaining employment and advancing lifelong learning. These graduate attributes include ethical and professional standards, expressed as "Understanding and a commitment to the highest ethical and environmental standards, sustainability, sensitivity to moral issues and conflicts, and relevant professional and environmental legislation and regulations".

While this intention is laudable, we might ask whether universities actually produce graduate geographers skilled for practical and ethical engagement with their scholarly, professional and personal worlds. If not, how can they? Currently the system allowing this is weak, and integration of ethical thought and practice into geography curricula in higher education is relatively ineffective, especially at undergraduate level.2 How can this situation be improved? In considering this challenge, the authors restrict the notion of ethics as ethical ways of thinking. This aligns well with geographical practice, providing ethics as practical reflection on professional and/or personal behaviour, rather than as higher level conceptual ethics or theorizing: we are concerned about ethics for living versus ethics for ethics' sake.

Academic integrity, rigor, fairness, and equity are integral to the geographer's working life. The ethics of the act of teaching are significant; an extensive literature on ethical and moral dimensions of school teaching makes this point. Among the characteristics of professionalism are self-regulation and the promotion of professional codes based on ethical principles (e.g. HEA, 2006; TDA, 2006), which, while these may be viewed as part of the new managerialism (Deem, 1998; Mahony \& Hextall, 2000; Nixon et al., 2001; Nixon 2003), may equally be seen as codifying traditional professional values or creating a new professionalism. Furthermore, teachers may differ significantly from other 
professionals in that they must be above moral censure: as their professional knowledge is about what constitutes a good life, they have ethical duties to students, the discipline, institutions, and the wider natural and social world to demonstrate the living of a 'good' life (Macfarlane, 2004). Geography educators, for example, should not just teach, for instance, sustainability, but live it. What we teach matters: we are communicating information that can affect young people's attitudes (Forsyth \& Maier, 2006). Our paper examines ethics in learning and teaching geography in universities, through reflection on our individual experiences as university academics, 3 providing examples of how ethics may be integrated into university geography curricula, thus offering suggestions to both academics and students as producers and consumers of geographical knowledge.

Because university teaching and research are so closely intertwined (a key defining character of university education), it is necessary to discuss research and ethics (e.g. Glassick et al., 1997; Healey, 2005; Le Heron et al., 2006). Teaching and learning about ethics is inevitably linked to research in two ways. First, issues of ethics are logically embedded in work done by the student as researcher, regardless of whether the research is input to coursework or research per se; student projects all engage students as producers of geographical knowledge and as co-researchers with their supervising academics. They share all the ethical considerations an academic must consider; this is especially so, and often explicit, in the apprenticeship model of research candidature and supervision, while it is more commonly only implicit, and unlikely to be acknowledged, in coursework studies. Second, ethics plays a central role for the student as a consumer and producer of geographical knowledge, where students need to understand the ethical considerations related to the research they are studying. In some parts of geography-notably the social and cultural geographies such as gender, queer, health and indigenous studies-this is explicit. Elsewhere-the physical geographies, for example-it may be less so, although recent trends towards professional training in geography (e.g. in environmental studies or management) place greater emphasis on professional codes and modes of conduct, themselves ethics-based.

\section{The Roles of Ethics and Ethical Considerations in Geography in Higher \\ Education}

In framing this issue, the authors' collective experience identifies a conceptual model of the role of ethics in university geography curricula. At present, ethics is at best patchy within the curriculum (Figure 1). Undergraduate and research postgraduate pathways are different, and connections between them weak or invisible. Ethics largely only impinges on research students via ethics clearance processes, which act as impediments and define methodology. Issues of ethics are, in many cases, invisible. The aim is to create ethical behaviour amongst research students and graduates, although this is usually better achieved through specific content rather than by underlying principle. The undergraduate pathway, alternatively, largely relies on implicit statements of ethical matters, with some (limited) introduction of ethics content into the curriculum; content is, at best, patchy, and rarely approaches any sequential development of ethical skills throughout a course. For many students ethical issues are never encountered. The result is the disengaged graduate.

How do we, as university geographers, progress to a pedagogical and curriculum situation that better aligns to achieving graduate outcomes such as those articulated in the introduction? In a desirable situation (Figure 2), undergraduate 
and postgraduate experiences would be closer and overlapping, with undergraduate pathways, for example, providing a stronger ethical basis for postgraduate studies, and the latter being more closely integrated into undergraduate curricula. Undergraduate studies would be designed to provide explicit, diverse and sequential development of ethical understanding and practices. This would require vertical development of ethical content (knowledge content, skills practices, and the evolution of scholarly behaviour) and horizontal alignment of content and practice throughout a degree program, enhancing students' skills of self-awareness and reflection. The result would be an empowered graduate with well-developed capacity for ethical decision-making and evolving personal attributes.

Figure 1. A conceptual model of the role of ethics and ethical matters in teaching and learning of geography in higher education, with the focus on the student as a consumer of geographic knowledge. The model is derived from the authors' collective experiences

Figure 2. A conceptual model of the role of ethics and ethical matters in an enhanced teaching and learning of geography in higher education, where the focus is on the student working towards the empowered graduate. This model reflects the collective experiences and aspirations of the authors

\section{Ethics-a Complex of Concepts and Behaviours}

Ethics, whether allied to a geography curriculum or applied more broadly, is a commonlyused label concerning a complex of concepts and behaviours (Israel \& Hay, 2006): "the systematic study of morality concerned with what it is to make a moral judgement" (Smith, 2000, p. 231). Kimmel (1988) distinguishes ethics as the distinction between right and wrong, from morals as usual or normal behaviour, effectively the distinction between metaethics and normative ethics. Metaethics concerns the "analysis or logic of moral concepts" (Hay, 1998, p. 57), and underlies moral views, seeking and exploring meaning and function of, and justification for, normative judgements: the meaning behind what is right and what is wrong. In contrast, the theory of normative ethics proposes solutions to moral problems; normative ethics offer the moral norms that guide what should or should not be done in situations (Hay, 1998, p. 57). This is the basis that generally underlies university ethics procedures.

Although Hay (1998, p. 57) argues that normative ethics are more important for "the day-to-day practice of geography", here we suggest it is important to consider both normative ethics and metaethics in addressing ethics within learning and teaching. Students need to understand both their own moral views and the foundations of ethical considerations, and the behavioural or normative aspects of ethical action, to develop appropriate levels of scholarly and professional behaviour and, in a geographic context, empathy for the people they work with and the environments they work in.

A further distinction is important. If we consider normative ethics as having institutional and personal components, then it is possible to view ethics as representing the structured and reasoned response to issues supported by academic bodies and codified in universities into mandated rules and procedures. On the other hand, morals encompass the judgements about issues or dilemmas that have to be made by an individual. Both ethics and morals combine to determine actions within research sensu lato, and have to be examined and cultivated when learning and teaching ethical practice within 
geography. Ethical positions may vary: whose side is the geographer on when acting as a geographer? Whose values are influencing him/her? What ideologies does he/she hold? What are his/her personal preferences for one type of method as opposed to another? (to paraphrase Denzin, 1970, pp. 341-342). Research and teacher positionality will affect the answer to these questions, as it indeed influences all of an academic's scholarly position (Cloke, 1994). Consideration of ethical bases and decision-making within geographical curricula provides a foundation for structured examination of positionality, thus allowing the student to engage the relationships between him/herself and his/her studies or research as social activities (cf. Cloke, 1994).

The literature on current ethical practice makes a convincing argument that prescriptive ethical procedures are "in fundamental opposition to moral thinking" (Hay \& Foley, 1998, p. 171). Research procedures used in universities are argued to induce a situation where, once ethical approval is achieved, the student or researcher is freed from the necessity to think ethically (Kearns et al., 1998). This position counters the logical ethical position of perceiving ethics as implicated in every part of the research process, teaching, and life. If this is the case, ethics clearance procedures can ultimately undermine ethical practice, and may defeat the reason for being. Common examples of the effects of ethics clearance on ethical practice include interesting spatial and temporal variations in what is deemed ethical within, for example, a single institutional committee, with similar studies being treated very differently on different submissions. For some researchers, it remains a puzzle that they are only required to obtain formal ethics approval when dealing directly with human participants or animals, whereas there can equally be ethical issues concerning the use of publicly available written and spoken information, computer software, taking samples from the field, etc. Equally puzzling can be the common practice of obtaining blanket approvals for undergraduate student projects or for teaching material used in teaching, or that ethics approval may not be required for research by non-academic organizations.

Peach (1995) argues how consequentialist and deontological approaches to normative ethics have dominated the Western world. Consequentialist approaches seek the greatest balance of good over evil; deontological approaches emphasize "collective rationality and the importance of moral laws as "categorical imperatives'" (Hay 1998, p.59). The latter view provides the basis of prescriptive procedures that universities and research bodies demand or encourage of researchers (e.g. ARC 2005; ESRC, 2005). Such frameworks for ethics tend to be better developed for research than for teaching. A recent Ethics Symposium (WACT, 2004), for example, asked: How do ethics impact on our everyday work as teachers? Why should teachers engage in discussion about ethics? Who should decide who guides our decision-making? Why does the teaching profession even want or need a Code of Ethics? In this context, it is unsurprising that the first real opportunity students have to learn about ethics is through submitting proposals to ethics committees for research work. This often has a negative learning outcome as students become entangled in bureaucratic procedures, blinding them to the positive advantages of best practice and the fundamental importance of appropriate behaviour. Ethics becomes a barrier or impediment to student progress rather than an enhancement, and makes the supervising academic's task harder. If for no other reason than this, it is incumbent on curricula to engage issues of ethics long before the student requires a bureaucratic encounter with ethics approval. 
Ethical meaning emerges from discourse, context and culture. There is an uneven ethical global landscape, often expressed as different expectations among different universities (Howitt 2005). The study by Healey et al. (2005) of students in the US, Australia and UK provides a good example. Ethical clearance is considered unnecessary for a test project in the UK, whereas the same project required ethics clearance in Australia. In the US different institutions may have widely varying ethics policies for students and faculty. One of the authors (Klein) has experienced parallel outcomes in the AAG's Center for Global Geography Education project in which collaboration between universities in Barcelona and Pennsylvania resulted in project design varied to be suited to each country's circumstances, variation that raised the ethical issue of inequitable treatment of students engaged in the project, given that some appeared to have learning opportunities denied others. It is clear that research is "undertaken in a social context, and ... cannot be divorced from its social and cultural settings" (Howitt, 2005, p. 319).

Prescriptive procedures and ethics committee advice, therefore, can lead to unethical actions within certain contexts (Grayson, 2004); confidentiality and anonymity, for example, cannot always be guaranteed from a legal perspective (Vujakovic \& Bullard 2001). The introduction of the recent anti-terrorism bill in the UK (Curtis \& Taylor, 2005) could make guaranteeing anonymity in certain contexts more difficult; similar conditions may apply in Australia with the recent re-writing of sedition laws (e.g. AVCC, 2006). Since early 2006, some US funding agencies have added stipulations that their funds not be used in any way to support terrorist groups. This highlights the differentiation introduced above between ethics and morals: "the moral person is not one who blindly follows ethical codes, no matter how enlightened" (Diener \& Crandalld 1978, p. 4). Ethical judgement becomes extremely personal, since "we all have very different personal or local views of what is right and wrong ... we have every right to follow what we feel is morally acceptable, unless it is harming another" (Robinson, 2005, p.6).

\section{An Example: Ethics, Vulnerable Groups, and Conducting Ethical Research with Refugees}

To put these ideas into a context, we provide a case study reflection on the comparative experiences of students and faculty as they engage with ethical practice in their research, drawing on Healey's and Hardwick's student-centred refugee research projects. Within research ethical procedures, refugees are frequently perceived to need greater protection than other groups. However, while it is important to consider how the research may address issues possibly not arising with other groups, working with refugees should not be considered distinctly different from working with any other group; all groups should be protected from harm. The overarching ethical view within refugee research is that research should be done with, rather than for or on refugees (Hynes, 2003). Working with potentially vulnerable people demands that researchers need "honest self-appraisal over motives, definitions, interpretations and accountability plateaus" (Teariki, 1992, p. 86). This provides the basis of our ethical reflections from two of the authors, a student and an academic respectively.

Healey's main dilemma in working with refugees is whether it is appropriate to intrude on the lives of particularly powerless people, just to complete a student project; this highlights a student's immediate agenda, his/her own scholarly development, against the subjects' needs. In disturbing people's lives, 
"information provided by the refugee must not only not be used to oppress, but if trust is to be restored, it must also be rendered meaningful" (Daniel \& Knudsen, 1995, p. 5). Healey's work raised several ethical issues: how to examine refugees' experiences without re-igniting the traumas that caused them to become refugees; the practical problem of identifying and accessing interviewees; and ensuring participants did not feel undue pressure to participate. Although all research provides the opportunity for participants to decline, it is often harder than it appears, or than academics think, to do so, especially for people whose understandings of English and academic culture may be limited. Healey also encountered ethical issues in writing up (e.g. Healey, 2006), where ethical clearance had proposed that interviewees were automatically given confidentiality (Kimmel, 1988); it was not anticipated that not all participants may want anonymity (Grinyer, 2002). The student's ethical clearance in this case was static, coming at one point in time, and consequently in conflict with the nature of ethical practice and the changing ethical issues arising within the research.

Hardwick's experience, from the perspective of a faculty member engaged in learning and teaching ethics, highlights the particular challenge of finding ways to work within an ethical framework on refugee research. She has directed graduate students on refugee issues in the US Pacific Northwest, documenting migration pathways, spatial patterns, and adjustment experiences of refugee groups now residing in the region. Hardwick's ethical issues largely reflect the dramatically changing international political situation, with tightening of refugee admissions policies and the imposition of Homeland Security restrictions. The project's research maps of refugee residential patterns have now become potentially dangerous political documents, and the project databases now contain information potentially useful to law-makers intent on tracking down socalled 'illegals'. Ethically, Hardwick finds herself caught between supporting the greater good of her students' research and larger questions of the safety and security of refugee communities. Although the project regularly submits to her university's Human Subjects Protocol for ethics clearance, the emerging politically charged issues are not accounted for in university policies. Hardwick has established, with refugee groups, a strict code of research ethics, but still questions whether this is enough to protect the lives of people who must safeguard their legal status and economic security in the world they now live in, and whether the public maps generated by the project give away too much information. Only one thing is clear, she claims: the lives and landscapes of vulnerable groups grow ever more vulnerable. By continuing to discuss, debate, and act upon concerns to protect interviewees, her group continues to hope that published and unpublished research outcomes will support rather than harm refugees.

\section{A Desirable Future: A Model for Enhancing the Ethical Capacity of Geography Students}

The key to including ethics in university geography is that, for ethics education to be relevant to the contemporary university geography student and to be effective in developing a new generation of ethical geographers, geography educators need to move from prescribed ethical practice towards embedded ethical considerations (see Figure 2). Ethics are, after all, "socially embedded, fluid, and contextual and that ethical practice cannot be routinized" (Hay 1998, p. 72). Ethical teaching within geography, therefore, needs to concentrate on teaching students to think ethically within the context of their own studies or research, so that they can be flexible in their approach to ethical practice where 
necessary. This then becomes part of a package allowing students greater selfdetermination and authority over their own scholarship and work, through their closer understanding of foundations and principles, and of their practical abilities in critical and informed analysis. Of course, this situation is neither easy nor unambiguous: "are we more interested in making ethical decisions on the basis of the consequences of our actions or on the basis of some notions of "justice'?" (Hay, 1998, p. 60). Perhaps the next generation of geographers will be better equipped to tackle and answer this question.

In general, work on ethics in higher education has focused on research rather than on learning and teaching. Hay (1998) calls for geographers to become a greater part of the debate on ethics in teaching and learning; Vujakovic \& Bullard (2001) provide useful ideas to assist in focusing on an ethics and teaching theme. Given both Hay's and Vujakovic and Bullard's comments we reflect on our own experiences here-especially Haigh's Ethical Geographer course development (below), Healey's and Hardwick's work with refugees and immigrants (above), and Boyd's broad-brush approach to integrating ethical considerations across scholarship (below). Equally, it would be possible to consider issues in geography laboratory settings, ethics in collaborative assignments, and ethics and problem-based learning. Within the literature, Hay and Foley's (1998) take on ethics and citizenship provides valuable contributions towards the goal of teaching ethical geography.

Alongside the inappropriateness of prescribed ethical practice, it is necessary to engage students with a responsibility to the 'Other' and to their moral selfconscience, rather than to the guardians of a code of ethics (Hay 1998). Such an approach sits comfortably with the growth of the new humanities (e.g. Fiske, 1989; Stock, 1993; Fuery \& Mansfield, 1997) and its influence on contemporary cultural geography and cultural influences on social geography (e.g. Short, 1991; Porteous, 1996; Gelder \& Jacobs, 1998). However, in the authors' countries, most teaching of ethics is still part of a research methods course. Such teaching is largely designed to meet prescribed institutional ethical procedures, in which an ethics lesson is often simply another tick box to the rest of the course, making ethics appear secondary to other curriculum content. More importantly, it runs the risk of focusing on bureaucratic aspects of ethics clearance, and thus creates an environment, as indicated above, in which students view ethics as a hindrance rather support for their research. By considering ethics this way, there is a serious risk that geography students are not recognized as moral active agents within their education and learning. Jackson (1993) argues that students should be re-conceptualized as embodied subjects rather than detached observers: teaching and learning ethics in geography becomes about educating 'responsible citizens' (Hay \& Foley, 1998), and thus ethics should be the basis of everything taught within geography, the foundation of the discipline. It is thus argued that ethics in university geography should be embedded in every part of the curriculum. In a contemporary geographical scholarly context, it is critical for ethics to emphasize empathy, and to be actively taught in collaboration with other faculty and students; this social aspect of teaching and learning emphasizes the core value of ethics as a social mechanism and process.

Two predominant loci of ethics can be found in undergraduate geographical curricula. First, where ethics are introduced into coursework they are largely subsumed into a broader agenda of 'cultural studies'. Cultural geography, as reconfigured over the last decades, fundamentally engenders issues of ethical and moral dilemmas, concerns for personal and group identity and expression of 
identity, the place of minority groups, and articulation of identities through behaviour within geographical and social space. Such an intellectual agenda is primarily concerned with issues of ethics, especially concerning relationships between people; students are thus confronted with ethical matters. Second, and especially with the growth of environmental management and studies within geography, ethics are introduced in the form of students' understanding and command of professional codes and behaviours; this, however, is more likely to take the form of training rather than reflective engagement. Boyd \& Taffs (2002, p. 259) for example, extol students to "conduct work in as environmentally a friendly way as possible, and adhere to relevant codes of practice ... and laws". They support this call with exercises for undergraduate students to collect examples of codes of ethics for different environmental disciplines, and to consider how, for example, such codes enhance fieldwork, and how they compare between academic and professional branches of the discipline.

\section{Embedding Ethics and Ethical Behaviour in Higher Education Geography Curricula}

Having argued that the inclusion of ethics and education of ethical thinking and practice within geographical curricula needs to be widened from the current narrow views of ethical practice within research, it remains to illustrate how this may be done. To close, we offer two illustrative case studies. The first draws on the experiences of one of the authors, Boyd, in introducing teaching and learning of ethics into his own geography courses and research. Some of this concerns non-ethics-specific curriculum adaptation. Environmental management teaching and learning, for example, often focuses upon technocratic and bureaucratic processes, and can become apparently value-neutral; it is the perfect medium for discussing and introducing matters of ethical concern. Boyd does this by raising issues of environmental concern, community and political action, and environmental custodianship (Boyd \& Laird, 2006), indigenous conceptions of environment, science as a social construction, and the roles and effects of social values on social behaviour, building on social construction theory (Jackson \& Penrose, 1993), and cognitive ownership (Boyd et al., 2005), methods that are not overtly 'ethical' but inevitably raise ethical questions, questions of personal relationships and responsibilities, appropriate behaviour, collaboration and cooperation in professional activities, the self versus the group, etc.

While intercultural and cross-cultural communication is not a mainstream component in many geography curricula, it is a fundamentally geographic phenomenon. Studies in indigenous geography provide ample opportunity to cover topics as varied as heritage and natural resource management to housing, and to develop students' inherent cultural awareness, empathy, and sensitivity (e.g. Boyd, 1996, 1999). In parallel to this, as a director of a local Aboriginal cultural mapping project, Boyd has had the opportunity to be explicit in clarifying relationships that we, as academics, have with Aboriginal communities. This has worked through a Memorandum of Understanding which redefined the roles of academics, the university, and the community as partners, in part articulating the notion that teaching and learning extends beyond the university to the community, democratizes scholarship and de-authorizes the academic as 'expert' and sole author (Greenwood \& Levin, 1998). Finally, Boyd makes considerable use of Cloke (1994) as a valuable trigger for students and staff starting to engage in personal reflection on their scholarship, encouraging all project students to compose short autobiographies as part of the methods section of their research reports; this has been extended to a short selfinterview exercise with three postgraduate students, in which the team reflected on the 
conceptual bases for their scholarship; the result was an, as yet, unpublished paper entitled "Finding a home: talking cultural geography".

\section{The Ethical Geographer: Developing a Coursework Ethics in Geography Module}

The second case study is a teaching module, The Ethical Geographer, recently introduced at Oxford Brookes University in the UK. This module examines an alternative way of teaching ethics in geography, and moves towards a greater emphasis on ethics within the university. The module articulates a particular interest in engaging more than just the ethics of the research, as is most commonly done by geographers. The focus is on geographers' activities as citizens, and the staff delivering this module try to address what one of the authors, Haigh, describes as "the wide-eyed and radical idea that the things geographers do could be more useful". Haigh was offered the opportunity to realize these ideas when his university department added a new course to the Honours component of its geography programme, a unit that he shares with a colleague. The module builds on four foundations: ethics (formally described), empathy (aspects of emotional intelligence and Emotional Quotient (EQ), environment (especially educational aspects of personal responsibility for sustainable development), and employment (which thus far basically refers to business ethics). It aims to encourage learners to consider their own personal goals and development, and the ambition is to persuade geography graduates to apply an ethical filter to everything they do, their studies, research and, more importantly, their everyday lives. The course first ran in 2006, and initial impressions are that the students seem content. The staff, however, are currently looking for other methods that can make this programme more effective.

In the module introduction, Haigh makes it clear that the module is designed to engage students in an exploration of what is described as "some largely unexplored territory", the students' self, equipping them with reflective tools and techniques to help them make the best of their own futures. The study guide introduction reminds students that the mark of a reflective practitioner is selfawareness, while the mark of a good citizen is conscience, one, it is hoped, that is clear because the citizen has self-evaluated his/her life and is satisfied that his/ her actions are right, appropriate and morally correct. The introduction does admit a more controversial concept, that "the mark of a successful person is someone who knows who they want to be in the future, who is able to rise above the rough and tumble of everyday life, and who can, ultimately, say I was the best that I could be for me, for others, and for my world". The module is presented as an honours-level course, and so contains higher level undergraduate challenges and expectations of academic skills, capabilities and maturity. It is anticipated that students will become autonomous and selfmotivated learners, with a solid grounding in a wide range of personal transferable skills: problem-solving, critical and lateral thinking, information retrieval, personal time management, team working and presentation. In other words, it addresses issues of ethics from a position of grounded reality and experience rather than theory, which is a strong behavioural or pragmatic process approach. Acknowledging that students will be entering "a realm where there are no easy answers and no universally accepted answers", it uses challenges to work out their own positions on key issues. Assessment is based on the skills with which they tackle the questions rather than specific answers themselves. Rather than prescribing ethical practices for students to research, 
this module aims to provide them with the skills to think ethically in all aspects of their lives.

The ethics component of the module introduces ethics as the systematic study of right and wrong, and so provides the framework for the whole module. The theme of empathy concerns the appreciation of beliefs and emotional understanding, and in doing so introduces students to psychogeography, the examination of landscapes in terms of their symbolic and emotional impact. However, at this stage, the module introduces a new, multicultural spin on the topic, an overview of ways different societies create their world picture; this emphasizes the contextual or positionality issues considered above. The environment component comprises what is probably the module's most explicit and conventional geographic content, paying homage to the United Nations Decade of Education for Sustainable Development, and concerning personal responsibilities and lifestyle and helping all people to live as if the future matters. This section also grants the opportunity for students to engage in practical environmental action through tree planting. Finally, the module turns to look at students' future, encouraging them to assess their current state and life goals through the writing of a personal statement; students need to reflect upon their current preparedness and needs and to construct a portfolio, such as they might need for a future employer, that illustrates their present capabilities and future potential.

\section{Conclusion}

This paper has come a long way. Commencing with a view that ethics is poorly integrated into university geography education, we have drawn on our own collective experiences, albeit in the Anglocentric university system, to identify impediments to integration of ethical education, and identify a desirable context for ethics education in geography curricula. We have drawn also on our experience to provide examples of engagement of ethical education in geography curricula, focusing on a practical or grounded approach rather than a theoretical one. It remains to be assessed whether we have, however, really answered the question posed above: How do we, as university geographers, progress to a pedagogical and curriculum situation that better aligns to achieving graduate outcomes such as those articulated in the introduction? While Figure 2 offers a schematic suggestion of a desirable position to be in, Haigh's module, for example, has yet to run long enough or to be evaluated critically to indicate if this is truly a model for a way forward. Likewise, our other experiences, drawn upon here to illustrate impediments, issues or small-scale teaching and learning approaches to the issue, have also yet to be fully tested. Nevertheless, they do represent a growing awareness of the need to better incorporate ethics education into university geography curricula.

\section{Acknowledgements}

The authors were all either present at the International Network for Learning and Teaching Geography in Higher Education (INLT) meeting in Brisbane (June 2006) or have communicated with the meeting group through the internet discussion. They acknowledge the many inputs provided by members of the INLT workshop and comments from others in the internet discussion. They especially wish to acknowledge the contributions and support of Eric Pawson and lain Hay.

Notes

1 This title draws from an illuminating statement in Israel \& Hay's recent book (2006, p. 1): "It is disturbing and not a little ironic that regulators and social 
scientists find themselves in this situation of division, mistrust and antagonism. After all we each start from the same point: that is, that ethics matter. Indeed, we share a view that ethics is about what is right, good and virtuous. None of us sets out to hurt people."

2 The author group considered this matter during the INLT workshop in Brisbane and its lead-up discussion, and while we focused in part on issues affecting the relative lack of teaching and learning of ethics in university geography criteria, and thus appear to be dwelling on the impediments to such curricula, it should be noted that we also discussed positive examples of how such obstacles and impediments to successfully integrating ethics into teaching geography could be overcome. This paper attempts to capture this balance.

3 We acknowledge that the authorship has a distinct Anglo-American-Australian emphasis. This will influence our discussion of issues, both culturally and pedagogically.

\section{References}

ARC (Australian Research Council) (2005) Research Ethics. Available at http://www.arc.gov.au/grant_programs/research_ethics.htm (accessed May 2006).

AVCC (Australian Vice-Chancellors' Committee) (2006) Media Releases 2006, 27 April 2006, Sedition Laws not appropriate for universities. Available at http://www.avcc.edu.au/content.asp?page $1 / 4$ /news/media releases/2006/avcc_media_15_06.htm (accessed May 200б).

Bondi, L. (2005) The place of emotions in research: from partitioning emotion and reason to the emotional dynamics of research relationships, in: J. Davidson, L. Bondi \& M. Smith (Eds) Emotional Geographies, pp. 231-246 (London: Ashgate).

Boyd, W. E. (1996) The significance of significance in cultural heritage studies: a role for cultural analogues in applied geography teaching. Journal of Geography in Higher Education, 20(3), pp. 295-304.

Boyd, W. E. (1999) Teaching cultural diversity to environmental science university students: Humanities-science culture clash and the relative effectiveness of three exercises confronting socio-cultural images and values, in: J. A. Kesby, J. M. Stanley, R. F. McLean \& L. J. Olive (Eds) Geodiversity: Readings in Australian Geography at the Close of the 20th Century, pp. 213-223 (Canberra: School of Geography \& Oceanography, Australian Defence Force Academy).

Boyd, W. E., Cotter, M. M., Gardiner, J. \& Taylor, G. (2005) Rigidity and a changing order... disorder, degeneracy and daemonic repetition: fluidity of cultural values and cultural heritage management, in: T. Darvill, C. Mathers \& B. Little (Eds) Heritage of Value, Archaeology of Renown: Reshaping Archaeological Assessment and Significance, pp. 89-113 (Gainesville: University Press of Florida).

Boyd, B. \& Laird, W. (2006) Analysing Global Environmental Issues: A Skills Manual, 2nd edn (Sydney: Pearson).

Boyd, B. \& Taffs, K. (2002) Mapping the Environment: A Professional Development Manual (Frenchs Forest: Pearson).

Cloke, P. (1994) (En)culturing political economy: a life in the day of a 'rural geographer', in: P. Cloke, M. Doel, D. Matless, M. Philips \& N. Thrift (Eds) Writing the Rural: Five Cultural Geographers, pp. 149-190 (London: Chapman).

Curtis, P. \& Taylor, M. (2005) Law-breakers in the library. Guardian, 8 November.

Daniel, E. V. \& Knudsen, J. C. (Eds) (1995) Mistrusting Refugees (Berkeley, CA: University of California Press). 
Deem, R. (1998) 'New managerialism' and higher education: the management of performances and cultures in the United Kingdom, International Studies in the Sociology of Education, 8(1), pp. 47-70.

Denzin, N. (1970) On ethics and the politics of doing sociology, in: The Research Act, pp. 314-343 (Chicago: Aldine).

Diener, E. \& Crandall, R. (1978) Ethics and Values in Social and Behavioural Research (Chicago: University of Chicago Press).

ESRC (2005) Research Ethics Framework (Swindon: Economic and Social Research Council).

Fiske, J. (1989) Understanding Popular Culture (London \& New York: Routledge).

Forsyth, A. S. \& Maier, J. N. (2006) Affective outcomes of a world geography course, Journal of Geography, 105(2), pp. 59-74.

Fuery, P. \& Mansfield, N. (1997) Cultural Studies and the New Humanities: Concepts and Controversies (Melbourne: Oxford University Press).

Gelder, K. \& Jacobs, J. M. (1998) Uncanny Australia: Sacredness and Identity in a Postcolonial Nation (Carlton South: Melbourne University Press).

Glassick, C. E., Huber, M. T. \& Maerof, G. I. (1997) Scholarship Assessed: Evaluation of the Professoriate (San Francisco: Jossey Bass).

Grayson, P. (2004) How ethics committees are killing survey research on Canadian students, University Affairs, Available at http://www.universityaffairs.ca (accessed January 2007).

Greenwood, D. J. \& Levin, M. (1998) Introduction to Action Research: Social Research for Social Change (Thousand Oaks, CA: Sage Publications).

Grinyer, A. (2002) The anonymity of research participants: assumptions, ethics and practicalities. Social Research Update 36. Available at http://www.soc.surrey.ac.uk/sru/SRU36.html (accessed January 2007).

Hay, I. (1998) Making moral imaginations: research ethics, pedagogy, and professional human geography, Ethics Place and Environment, 1(1), pp. 5576.

Hay, I. \& Foley, P. (1998) Ethics, geography and responsible citizenship, Journal of Geography in Higher Education, 22(2), pp. 169-183.

HEA. (Higher Education Academy) (2006) The UK Professional Standards Framework for Teaching and Supporting Student Learning in Higher Education (Higher Education Academy, York). Available at http//:www.heacademy.ac.uk/regandaccr/StandardsFramework.pdf (accessed February 2006).

Healey, M. (2005) Linking research and teaching to benefit student learning, Journal of Geography in Higher Education, 29(2), pp. 183-201.

Healey, M., Kneale, P. \& Bradbeer, J. (2005) Learning styles among geography undergraduates: an international comparison, Area, 37(1), pp. 30-47.

Healey, R. L. (2006) Asylum seekers and refugees: a structuration theory analysis of their experiences in the UK, Population, Space and Place, 12(4), pp. 257-271.

Howitt, R. (2005) Human ethics, supervision and equity: ethical oversight of student research, Journal of Geography in Higher Education, 29(3), pp. 317320.

Hynes, T. (2003) The issue of 'trust' or 'mistrust' in research with refugees: choices, caveats and considerations for researchers, New Issues in Refugee Research (London: UNHCR).

Israel, M. \& Hay, I. (2006) Research Ethics for Social Scientists (London: Sage Publications). Jackson, P. A. (1993) Changing ourselves: a geography of position, in: R. J. Johnston (Ed.) The Challenge for Geography, pp. 198-214 (Oxford: Blackwell). 
Jackson, P. A. \& Penrose, J. (Eds) (1993) Constructions of Race, Place and Nation (London: UCL Press).

Kearns, R., Le Heron, R. \& Romaniuk, A. (1998) Interactive ethics: developing understanding of the social relations of research, Journal of Geography in Higher Education, 22(3), pp. 297-310.

Kimmel, A. J. (1988) Ethics and Values in Applied Social Research (London: Sage Publications).

Le Heron, R., Baker, R. \& McEwen, L. (2006) Co-learning: re-linking research and teaching in geography, Journal of Geography in Higher Education, 30(1), pp. 77-87.

Macfarlane, B. (2004) Teaching with Integrity: The Ethics of Higher Education Practice (London: Routledge).

Mahony, P. \& Hextall, I. (2000) Reconstructing Teaching: Standards, Performance and Accountability (London: Routledge).

Nixon, J. (2003) Professional renewal as a condition of institutional change: a manifesto of hope, International Studies for the Sociology of Education, 13(1), pp. 3-15.

Nixon, J., Marks, A., Rowland, S. \& Walker, M. (2001) Towards a new academic professionalism: a manifesto of hope, British Journal of Sociology of Education, 22(2), pp. 227-244.

Peach, L. (1995) An introduction to ethical theory, in: R. L. Penslar (Ed.) Research Ethics: Cases and Materials, pp. 13-26 (Bloomington: Indiana University Press).

Porteous, J. D. (1996) Environmental Aesthetics: Ideas, Politics and Planning (London \& New York: Routledge). Robinson, S. (2005) Ethics and employability, in: Learning and Employability, pp. 1-25 (York: Higher Education Academy). Available at http://www.heacademy.ac.uk/resources.asp?process $1 / 4$ full_record\& section $1 / 4$ generic\&id $1 / 4584$ (accessed October 2007).

Short, J. R. (1991) Imagined Country: Society, Culture and Environment (London and New York: Routledge).

Smith, D. M. (2000) Geography and ethics, in: R. J. Johnston, D. Gregory, G. Pratt $\&$ M. Watts (Eds) The Dictionary of Human Geography, 4th edn, pp. 231-234 (Oxford: Blackwell).

Stock, B. (1993) Reading, community and a sense of place, in: D. Duncan \& D. Ley (Eds) Place/Culture/Representation, pp. 314-328 (London and New York: Routledge).

TDA (Training and Development Agency) (2006) Professional Standards for Classroom Teachers (London: Training and Development Agency). Available at http:www.tda.gov.uk/upload/pdf/d/draft revised standards_for_classroom_teachers_6_apr_06.pdf (accessed June 2006).

Teariki, C. (1992) Ethical issues in research from a Maori perspective, New Zealand Geographer, 48(2), pp. 85-86.

Vujakovic, P. \& Bullard, J. (2001) The ethics minefield: issues of responsibility in learning and research, Journal of Geography in Higher Education, 25(2), pp. 275-283.

WACT (Western Australian College of Teaching) (2004) Ethics for the Teaching Profession. Available at http:// www.collegeofteaching.wa.edu.au/ethics.html (accessed May 2006). 